\title{
Reasons for nonuse of contraceptive methods by women with demand for contraception not satisfied: an assessment of low and middle-income countries using demographic and health surveys
}

\author{
Laísa Rodrigues Moreira ${ }^{1}$, Fernanda Ewerling ${ }^{2}$, Aluisio J. D. Barros ${ }^{1,2}$ and Mariangela Freitas Silveira ${ }^{1 *}$ (D)
}

\begin{abstract}
Background: Nonuse of contraceptive methods by women in need of contraception may impact their sexual and reproductive health. The aim of this study was to describe the reasons for nonuse of contraception among women with demand for contraception not satisfied in low and middle-income countries (considering both overall countries and various subgroups of women).

Methods: We used the latest Demographic and Health Survey data from 47 countries. A descriptive analysis of the reasons for nonuse of contraceptive methods was performed among sexually active women with demand for contraception not satisfied. The prevalence of each reported reason was also evaluated according to marital status, woman's age and schooling, area of residence, wealth index, and parity. Wealth-related absolute inequality for each reason was also evaluated using the Slope Index of Inequality. A pro-rich inequality pattern means that the reason is more prevalent among the richest women while a pro-poor means the reason is more common among the poorest ones.

Results: On average, $40.9 \%$ of women in need of contraception were not using any contraceptive methods to avoid pregnancy. Overall, the most prevalent reasons for nonuse of contraceptives were "health concerns" and "infrequent sex," but the prevalence of each reason varied substantially across countries. Nonuse due to "opposition from others" was higher among married than unmarried women; in turn, the prevalence of nonuse due to "lack of access" or "lack of knowledge" was about two times higher in rural areas than in urban areas. Women with less schooling more often reported nonuse due to "lack of access." Pro-rich inequality was detected for reasons "health concerns," "infrequent sex," and "method-related", while the reasons "other opposed," "fatalistic," "lack of access," and "lack of knowledge" were linked to patterns of pro-poor inequality.
\end{abstract}

Conclusions: Family planning promotion policies must take into account the different reasons for the nonuse of contraceptive methods identified in each country as well as the contextual differences regarding women of reproductive age (such as social norms and barriers that prevent women from accessing and using contraceptives).

Keywords: Contraception, Family planning, Reproductive health, Socioeconomic factors, Health inequalities

\footnotetext{
* Correspondence: mariangelafreitassilveira@gmail.com

'Postgraduate Program in Epidemiology, Federal University of Pelotas,

Marechal Deodoro, 1160 - 3rd floor. Centro, Pelotas 96020-220, Brazil

Full list of author information is available at the end of the article
}

(c) The Author(s). 2019 Open Access This article is distributed under the terms of the Creative Commons Attribution 4.0 International License (http://creativecommons.org/licenses/by/4.0/), which permits unrestricted use, distribution, and reproduction in any medium, provided you give appropriate credit to the original author(s) and the source, provide a link to the Creative Commons license, and indicate if changes were made. The Creative Commons Public Domain Dedication waiver (http://creativecommons.org/publicdomain/zero/1.0/) applies to the data made available in this article, unless otherwise stated. 


\section{Plain English summary}

The nonuse of contraceptive methods by women who need contraception may impact the lives of these women and the planning of their families. One example is unintended pregnancy and its possible implications. Research has identified several reasons for the nonuse of contraceptive methods. However, studies have mostly only focused on women who are married or who live with a partner. In this study, we included all sexually active women in each country; doing so allowed a more comprehensive overview of the reasons for why women whose demands for contraception are not satisfied do not use contraceptive methods. We presented the differences between the reasons for nonuse of contraceptives reported by partnered and unpartnered women. Data from 47 low and middle-income countries were obtained from the Demographic and Health Survey (DHS) Program for analysis. The results showed that, on average, about four out of ten women in need of contraception were not using any contraceptive methods. There was great variation among countries in the reasons reported. Overall, the most common reasons for nonuse were "health concerns" and "infrequent sex." Nonuse due to "opposition from others" was more common among married women. It was noteworthy that wealthier women often mentioned "health concerns," "infrequent sex," and "method-related" as reasons for not using contraceptives. The present research is important in helping professionals from various fields understand why women who need contraception do not use contraceptive methods so as to offer guidance and provide adequate care.

\section{Background}

The nonuse of contraceptive methods by people who need contraception has been associated with potential implications at the individual, familial, community, and global levels. Sustainable Development Goals [1], as well as the proposal of maternal and child health indicators [2], have been essential in increasing the visibility of this topic and highlighting points for improvement. In addition, several agencies and organizations around the world have engaged in global efforts to finance actions that promote family planning, especially in low and middle-income countries (LMIC) [3-5].

However, despite these efforts, the sexual and reproductive rights of women are not always respected. Although there is evidence of progressive increases in the use of contraceptive methods [6], many women still face various barriers to contraceptive use [7]. It is estimated that 214 million women in LMIC in need of contraception do not use any modern contraceptive methods [8]. Considering that all women, as advocated by the Sustainable Development Goals, should have access to sexual and reproductive health services, understanding the reasons behind why this need remains unfulfilled is essential for action planning.

An investigation performed by Sedgh and Hussain [9] on 51 LMIC showed that among married women, the most frequent reasons for nonuse of contraceptives were low frequencies of sexual relations, and fears of side effects and potential health risks. However, a major limitation of that study is the absence of unmarried, sexually active women in the study sample. The reasons for nonuse are likely very different between married and unmarried women, and this is possibly linked to social barriers and other difficulties related to access to contraceptives that unmarried women face. However, literature concerning family planning lacks information regarding reasons, reported by the women themselves, for not using contraception. As discussed by Sedgh and Hussain [9], the analysis of the reasons for nonuse in different population subgroups may provide relevant information to support the design of specific initiatives. Added to that, there is increasing evidence in scientific literature of the importance of using measures that are not only expressed as aggregate data [10], that is, of evaluating the specificities of each country and the possible inequality contexts.

Considering the situation, the present work aimed to address this gap in knowledge. In addition to evaluating the reasons for nonuse of contraceptive methods by sexually active women with demand for contraception not satisfied in LMIC, subgroup analyses of the reasons for nonuse were performed to investigate possible barriers and to propose strategic priorities to improve women's sexual and reproductive health. Furthermore, the analyses of inequalities might identify what strategies may be more suitable for each subgroup.

\section{Methods}

We analyzed data from the Demographic and Health Surveys (DHS) Program for 47 countries. The study focused on the most recent surveys, with data collected in and after 2010, to provide a current overview of the topic investigated. The Multiple Indicator Cluster Surveys (MICS) were not included, since the data of interest could not be retrieved from these surveys in a manner that allowed for comparison. DHS are standardized surveys that use a cross-sectional design to collect data from LMIC. All surveys use similar questionnaires, methodology, and sampling strategies, which ensures the comparability of results. In general, the areas of interest are initially identified through censuses or other procedures. After that, households are selected based on preestablished methodological steps $[11,12]$. The present analysis included the latest available DHS with information on demands for family planning and covered all 
sexually active women of reproductive age (15-49 years) in each country. Six surveys that did not contain information on sexually active women living without a partner were excluded (Afghanistan 2015, Bangladesh 2014, Egypt 2014, Jordan 2012, Pakistan 2012, Yemen 2013).

\section{Definitions and outcomes}

The study's primary outcomes were the reasons reported by sexually active women of reproductive age (15-49 years) (with demand for contraception not satisfied) for not using contraceptive methods. The indicator Demand for Contraception Not Satisfied utilizes the number of women who are not using any contraceptive methods in its numerator and the number of women of reproductive age (15-49 years) in need of contraception in its denominator. In other words, the study included women who were in need of contraception but did not use any contraceptive methods. Women in need of contraception were defined as those who were sexually active and fertile, but did not intend to become pregnant in the next 2 years or did not know if or when they intended to become pregnant $[2,11,13]$. Sexually active women were defined as those who were married or lived with a partner and those who were not married but had sexual intercourse in the 30 days prior to the survey. Infertile women excluded from the study were defined as those who: 1) had never had a period or were amenorrhoeic in the 6 months before the survey even though they were not in the postpartum period, 2) were hysterectomized, and 3) had been married or in a stable relationship for 5 years or more but did not become pregnant despite a lack of contraceptive use [11, 14]. Although pregnant women who considered their pregnancies untimely or had not desired their pregnancies are generally classified as in need of contraception [11], they were also excluded from this study because being pregnant is one of the filters for the questions regarding the reasons for nonuse of contraception.

The reasons for nonuse were evaluated using the following question: "You have said that you do not want any (more) children. Can you tell me why you are not using a method to prevent pregnancy? Any other reason?" The reasons for not using contraceptive methods were grouped into eight broad groups of reasons (see Table 1 for details): 1) "respondent opposed" (i.e., the woman herself opposed contraceptive use), 2) "other opposed," 3) "lack of knowledge," 4) "health concerns," 5) "lack of access," 6) "method-related" (inconvenient to use), 7) "fatalistic" (or up to God, meaning that the woman feels that pregnancies are determined by fate), and 8) "infrequent sex." Because women could report more than one reason, each response category was analyzed separately.
Table 1 Operational definition of the reasons for not using contraceptive methods

\begin{tabular}{ll}
\hline Outcomes (reasons) definition & Reasons included \\
\hline 1) Respondent opposed & Respondent opposed \\
2) Other opposed & Husband or partner opposed \\
& Others opposed \\
& Religious prohibition \\
3) Lack of knowledge & Knows no method \\
& Knows no source \\
4) Health concerns & Health concern \\
& Fear of side effects \\
5) Lack of Access & Interferes with bodily processes \\
& Too far \\
& Costs too much \\
6) Method-related & No method available \\
7) Fatalistic & Preferred method not available \\
8) Infrequent sex & Method is inconvenient to use \\
& Fatalistic \\
\hline & Not having sex \\
& Infrequent sex \\
\hline
\end{tabular}

\section{Statistical analysis}

Descriptive analyses were used to identify the main reasons for the nonuse of contraceptive methods among women whose demands for contraception were not satisfied in the various LMIC. When analyzing the reasons for nonuse, the countries were ranked according to the level of demand for contraception not satisfied: less than $30.0 \%, 30.0 \%$ to $50.0 \%$, and more than $50.0 \%$. Considering these coverage levels, the reasons for nonuse were also evaluated according to the following stratification variables:

- marital status (married/union; unmarried sexually active);

- woman's age (15 to $19 ; 20$ to $34 ; 35$ to 49 years);

- area of residence (urban or rural);

- woman's education (none; primary/elementary school; secondary or higher);

- parity defined as the number of live births $(0 ; 1-2 ; 3$ or more);

- wealth index (in quintiles, with the first corresponding to the poorest $20 \%$ and the fifth to the wealthiest $20 \%$ in each country). The wealth index is calculated using principal component analyses which take into account characteristics of the household, ownership of selected assets, and educational attainment of the head of the family $[15,16]$.

In addition, inequality analyses were performed using the Slope Index of Inequality (SII). Instead of calculating 
the simple absolute difference in the prevalence of the outcome of interest in the wealthiest vs. poorest quintile, the SII measures the difference in predicted coverage using a statistical model for these quintiles. In other words, the SII takes into account the prevalence of the outcome of interest in the five wealth quintiles to estimate the absolute difference between the wealthiest and the poorest quintile $[15,16]$. All statistical analyses were performed using the STATA 13.1 statistical package [17] and took into account the sample weights of surveys through the command "svy."

\section{Results}

Considering the 47 countries analyzed, the mean prevalence of demand for contraception not satisfied was 40.9\% (95\% CI: 38.9-43.0). Seventeen countries had a prevalence of demand for contraception not satisfied higher than 50\%, and in five of these countries (Angola, Mali, Gambia, Guinea, and Chad), the prevalence was $70 \%$ or higher. The Republic of Chad had the highest prevalence (79.7\%, 95\% CI: 77.2-82.1) (Table 2). The two countries with the lowest prevalence of demand for contraception not satisfied were Colombia (8.6\%, 95\% CI: $8.1-9.2)$ and Honduras (12.8\%, 95\% CI: 12.1-13.5), both located in Latin America and the Caribbean.

"Health concerns" was the top reason for nonuse in 22 out of the 47 countries. In 18 countries $(38.3 \%$ of the total countries), "infrequent sex" was the most prevalent reason (Table 3). In Gabon, the same prevalence (17.4\%) was recorded for both "health concerns" and "infrequent sex," and the two were also the most common reasons for nonuse in this country. "Other opposed" was the most prevalent reason in three countries (Senegal, Mali, and Guinea). In Gambia, "respondent opposed" was the most prevalent reason for nonuse whereas in Ethiopia and Niger, "fatalistic" was the most common reason (Table 3).

The prevalence of the reasons reported were also different according to the level of demand for contraception not satisfied (Table 3). On average, "health concern" and "infrequent sex" were the most common reasons for all levels of demand not satisfied, but the prevalence of these reasons was higher among countries with demand not satisfied below $30 \%$. All the other reasons tended to be more prevalent among countries with higher demand not satisfied.

It is important to note that the most common reasons for nonuse of contraception varied greatly between countries. In the five countries with demand not satisfied of $70 \%$ or more, the most prevalent reasons for nonuse were: Angola - "health concerns" (13.3\%, 95\% CI: 11.115.9), Mali - "other opposed" (26.4\%, 95\% CI: 22.7-30.5), Gambia - "respondent opposed" (25.4\%, 95\% CI: $21.2-$ 30.0), Guinea - "other opposed" (15.5\%, 95\% CI: $13.3-$
18.0), and Chad - "infrequent sex" (18.0\%, 95\% CI: $15.7-$ 20.5).

Stratification provided an overview of the situation in the countries according to different subgroups of women. These analyses are presented by level of demand for contraception not satisfied: countries with demand not satisfied below 30\% (Fig. 1), from 30\% to 50\% (Fig. 2), and above $50 \%$ (Fig. 3). We also provide the stratified estimates for each reason by country in the supplementary material (see Additional files 1, 2, 3, 4, 5, 6, 7 and 8). These analyses reveal important differences on why some women do not use contraception.

Nonuse due to "health concerns" was more frequently reported among women who were older, had higher levels of education, had more wealth, were married or living with a partner, had at least one child, and among those living in urban areas. "Infrequent sex," the second most reported reason, was higher among those who had higher levels of education, had more wealth, were unmarried, and had no children. In all the coverage levels assessed, a difference close to eight percentage points was observed for the comparison between married and unmarried women in "infrequent sex," with the latter being more likely to mention this reason (Figs. 1, 2 and 3).

There were no marked inequalities in the reporting of nonuse due to "respondent opposed." On the other hand, nonuse as a result of "other opposed" occurred mostly among married women rather than unmarried women in all coverage levels assessed. However, the prevalence of this reason was higher among countries with higher demand not satisfied. For those with demand not satisfied of $>50 \%$, "opposition by others" was reported by $15.1 \%$ of married women and $8.5 \%$ of unmarried women (Fig. 3) while for countries with demand not satisfied of $<30 \%$, this reason was reported by $7.8 \%$ of married women and $3.6 \%$ of unmarried women (Fig. 1). In countries with demand not satisfied between 30 and $50 \%$, there were higher inequalities observed in terms of wealth and education; poorer and less educated women were more likely to report this reason (Fig. 2).

Nonuse due to "fatalistic," "lack of access," and "lack of knowledge" were more frequently reported by women in the poorer groups, those with lower education levels, and those who lived in rural areas (Figs. 1, 2 and 3). "Fatalistic" as the reason for nonuse was also systematically higher among older women and those with higher parity. "Lack of knowledge" was also about twice higher in rural areas than in urban areas for all levels of demand for contraception not satisfied evaluated. Nonuse due to "lack of access" was also higher in rural areas than in urban areas for all levels of demand for contraception not satisfied $(<30 \%, 30-50 \%$ and $>50 \%)$, corresponding to, respectively, $5.3 \%, 3.5 \%$, and $4.6 \%$ in urban areas, and 6.3\%, 6.1\%, and $8.0 \%$ in rural areas (Figs. 1, 2 and 3). 
Table 2 Overall description (countries information, prevalence of demand for contraception not satisfied and 95\% Cl)

\begin{tabular}{|c|c|c|c|c|c|}
\hline Country & Year & ISO & Region & Income group & $\begin{array}{l}\text { Demand for contraception } \\
\text { not satisfied } \%(95 \% \text { Cl) }\end{array}$ \\
\hline \multicolumn{6}{|c|}{ Prevalence of demand for contraception not satisfied $<30.0 \%$} \\
\hline Colombia & 2015 & $\mathrm{COL}$ & Latin America and Caribbean & Upper-middle income & $8.6(8.1-9.2)$ \\
\hline Honduras & 2011 & HND & Latin America and Caribbean & Lower-middle income & $12.8(12.1-13.5)$ \\
\hline Zimbabwe & 2015 & ZWE & Eastern and Southern Africa & Low income & $14.0(12.8-15.4)$ \\
\hline Dominican Republic & 2013 & DOM & Latin America and Caribbean & Upper-middle income & $14.6(13.0-16.3)$ \\
\hline Indonesia & 2012 & IDN & East Asia and the Pacific & Lower-middle income & $15.6(14.8-16.4)$ \\
\hline Armenia & 2015 & ARM & Europe and Central Asia & Lower-middle income & $17.9(16.2-19.6)$ \\
\hline Cambodia & 2014 & KHM & East Asia and the Pacific & Low income & $18.2(16.9-19.6)$ \\
\hline Guatemala & 2014 & GTM & Latin America and Caribbean & Lower-middle income & $18.7(17.7-19.8)$ \\
\hline India & 2015 & IND & South Asia & Lower-middle income & $19.4(19.1-19.6)$ \\
\hline Namibia & 2013 & NAM & Eastern and Southern Africa & Upper-middle income & $20.8(19.2-22.4)$ \\
\hline Lesotho & 2014 & LSO & Eastern and Southern Africa & Lower-middle income & $23.1(21.3-25.1)$ \\
\hline Kenya & 2014 & KEN & Eastern and Southern Africa & Lower-middle income & $23.6(22.3-25.0)$ \\
\hline Myanmar & 2015 & MMR & East Asia and the Pacific & Lower-middle income & $23.8(22.3-25.3)$ \\
\hline Philippines & 2017 & $\mathrm{PHL}$ & East Asia and the Pacific & Lower-middle income & $24.3(23.0-25.6)$ \\
\hline Malawi & 2015 & MWI & Eastern and Southern Africa & Low income & $25.2(24.2-26.3)$ \\
\hline Congo Brazzaville & 2011 & COG & West and Central Africa & Lower-middle income & $26.2(24.2-28.2)$ \\
\hline Rwanda & 2014 & RWA & Eastern and Southern Africa & Low income & $27.7(26.2-29.3)$ \\
\hline \multicolumn{6}{|c|}{ Prevalence of demand for contraception not satisfied 30.0-50.0\% } \\
\hline Nepal & 2016 & NPL & South Asia & Low income & $31.1(29.6-32.5)$ \\
\hline Zambia & 2013 & ZMB & Eastern and Southern Africa & Lower-middle income & $32.3(30.8-33.8)$ \\
\hline Kyrgyzstan & 2012 & KGZ & Europe and Central Asia & Low income & $33.7(31.3-36.1)$ \\
\hline Tanzania & 2015 & TZA & Eastern and Southern Africa & Low income & $35.9(34.0-37.8)$ \\
\hline Ethiopia & 2016 & ETH & Eastern and Southern Africa & Low income & $38.1(35.1-41.3)$ \\
\hline Gabon & 2012 & GAB & West and Central Africa & Upper-middle income & $41.5(38.0-45.0)$ \\
\hline Uganda & 2016 & UGA & Eastern and Southern Africa & Low income & $41.8(40.2-43.4)$ \\
\hline Senegal & 2017 & SEN & West and Central Africa & Low income & $44.1(41.9-46.3)$ \\
\hline Mozambique & 2015 & MOZ & Eastern and Southern Africa & Low income & $44.6(41.7-47.5)$ \\
\hline Tajikistan & 2012 & TJK & Europe and Central Asia & Low income & $45.0(42.7-47.4)$ \\
\hline Cameroon & 2011 & CMR & West and Central Africa & Lower-middle income & $46.4(44.4-48.5)$ \\
\hline Nigeria & 2013 & NGA & West and Central Africa & Lower-middle income & $47.7(45.8-49.6)$ \\
\hline Timor-Leste & 2016 & TLS & East Asia and the Pacific & Lower-middle income & $49.7(47.0-52.4)$ \\
\hline \multicolumn{6}{|c|}{ Prevalence of demand for contraception not satisfied $>50.0 \%$} \\
\hline Burundi & 2016 & $\mathrm{BDI}$ & Eastern and Southern Africa & Low income & $50.9(49.1-52.7)$ \\
\hline Sierra Leone & 2013 & SLE & West and Central Africa & Low income & $52.0(48.9-55.1)$ \\
\hline Ghana & 2014 & GHA & West and Central Africa & Lower-middle income & $52.1(49.6-54.7)$ \\
\hline Niger & 2012 & NER & West and Central Africa & Low income & $53.5(50.6-56.5)$ \\
\hline Haiti & 2016 & $\mathrm{HTl}$ & Latin America and Caribbean & Low income & $53.9(52.0-55.7)$ \\
\hline Congo Democratic Republic & 2013 & COD & West and Central Africa & Low income & $56.4(53.0-59.7)$ \\
\hline Côte d'Ivoire & 2011 & CIV & West and Central Africa & Lower-middle income & $58.0(55.0-61.0)$ \\
\hline Burkina Faso & 2010 & BFA & West and Central Africa & Low income & $58.8(56.8-60.8)$ \\
\hline Liberia & 2013 & LBR & West and Central Africa & Low income & $59.0(55.3-62.7)$ \\
\hline Togo & 2013 & TGO & West and Central Africa & Low income & $60.8(58.5-63.1)$ \\
\hline
\end{tabular}


Table 2 Overall description (countries information, prevalence of demand for contraception not satisfied and 95\% Cl) (Continued)

\begin{tabular}{llllll}
\hline Country & Year & ISO & Region & Income group & $\begin{array}{l}\text { Demand for contraception } \\
\text { not satisfied \% (95\% Cl) }\end{array}$ \\
\hline Comoros & 2012 & COM & Eastern and Southern Africa & Low income & $61.2(57.7-64.6)$ \\
Benin & 2011 & BEN & West and Central Africa & Low income & $69.6(68.0-71.2)$ \\
Angola & 2015 & AGO & Eastern and Southern Africa & Upper-middle income & $70.7(67.6-73.7)$ \\
Mali & 2012 & MLI & West and Central Africa & Low income & $71.0(68.6-73.3)$ \\
Gambia & 2013 & GMB & West and Central Africa & Low income & $72.9(69.4-76.1)$ \\
Guinea & 2012 & GIN & West and Central Africa & Low income & $75.7(73.0-78.2)$ \\
Chad & 2014 & TCD & West and Central Africa & Low income & $79.7(77.2-82.1)$ \\
\hline
\end{tabular}

Regarding the inequality among the reasons for not using contraceptive methods by country, determined by the SII, the results clearly show that nonuse due to "health concerns," "infrequent sex," and "method-related" showed pro-rich inequality patterns $(\mathrm{SII}>0)$ in most countries, which means that these reasons were more prevalent among the richest women (see Additional file 9). On the other hand, the reasons "other opposed," "fatalistic," "lack of access," and "lack of knowledge" were linked to patterns of pro-poor inequality $(\mathrm{SII}<0)$, which means that these reasons were more prevalent among the poorest women.

\section{Discussion}

This study evaluated the reasons for nonuse of contraception among women with demand for contraception not satisfied in $47 \mathrm{LMIC}$. The mean prevalence of demand for contraception not satisfied in this group of countries was $40.9 \%$ (95\% CI: 38.9-43.0). Regarding the reasons for nonuse by women with demand for contraception not satisfied, it is noteworthy that "health concerns" and "infrequent sex" were the most prevalent reasons in many countries. Five countries, all of which are located in Africa (Angola, Chad, Gambia, Guinea and Mali), presented prevalence of demand not satisfied of $>70.0 \%$.

In West and Central Africa, where many of the lowincome countries analyzed are located, a study identified inequalities and a higher probability of long-term contraceptive use by the wealthier women in this region than by the poorer women [18]. This underscores the need to empower women and the importance of learning about the unique characteristics of each region, for example.

Conversely, Colombia (8.6\%, 95\% CI: 8.1-9.2) and Honduras (12.8\%, 95\% CI: 12.1-13.5), located in Latin American and the Caribbean, had the lowest prevalence of demand for contraception not satisfied. The literature on Latin America and the Caribbean describes a decline in fertility rate over time [19] as well as other demographic changes, such as aging populations [20]. In this context, reproductive health policies, among other strategies, play an important role in family planning [21].
Some advances also may be attributed to the availability of a variety of contraceptive methods [20]. It is possible that these various processes together may explain the low levels of demand for contraception not satisfied identified in Colombia and Honduras. However, it is important to highlight that the low prevalence of demand for contraception not satisfied in these countries do not reflect an ideal scenario, although some of these countries have low levels of demand not satisfied, the optimal prevalence for this indicator would be zero. All women in need of contraceptives should have access to them.

Practicing contraception does have side effects, and nonuse due to fear of these consequences was addressed in the reason "health concerns." Conversely, one possible result of not using any contraceptive methods is unintended pregnancy [22]. It should be noted that, besides the associated stigma, unintended pregnancy may have other consequences for the woman and her family of which the general population is often unaware. Such consequences may include negative health outcomes for the woman (morbidity and mortality) and the child (for example, impact on prenatal care and breastfeeding) as well as social costs [23-25]. However, it should be noted that unintended pregnancies are not always regarded as negative outcomes by women and their families, which shows the importance of contextual variables [26]. Nevertheless, studies also suggest that the possible side effects of contraceptive use are few compared to the possible risks resulting from some types of pregnancies [27-29].

Women in the highest wealth quintile had a higher mean prevalence of nonuse due to "health concern." This raises the question of whether these women have access to a wide range of contraceptive methods or whether this access is restricted to only a few contraceptive options that may not meet individual demands. In this study, we showed that some participants mentioned "method-related" reasons for not using contraceptives which may indicate dissatisfaction with the existing methods of contraception; this supports the need for a wider range of contraceptive options, as pointed out by Barot [30]. In addition, health care professionals need to provide evidence-based information about the methods 


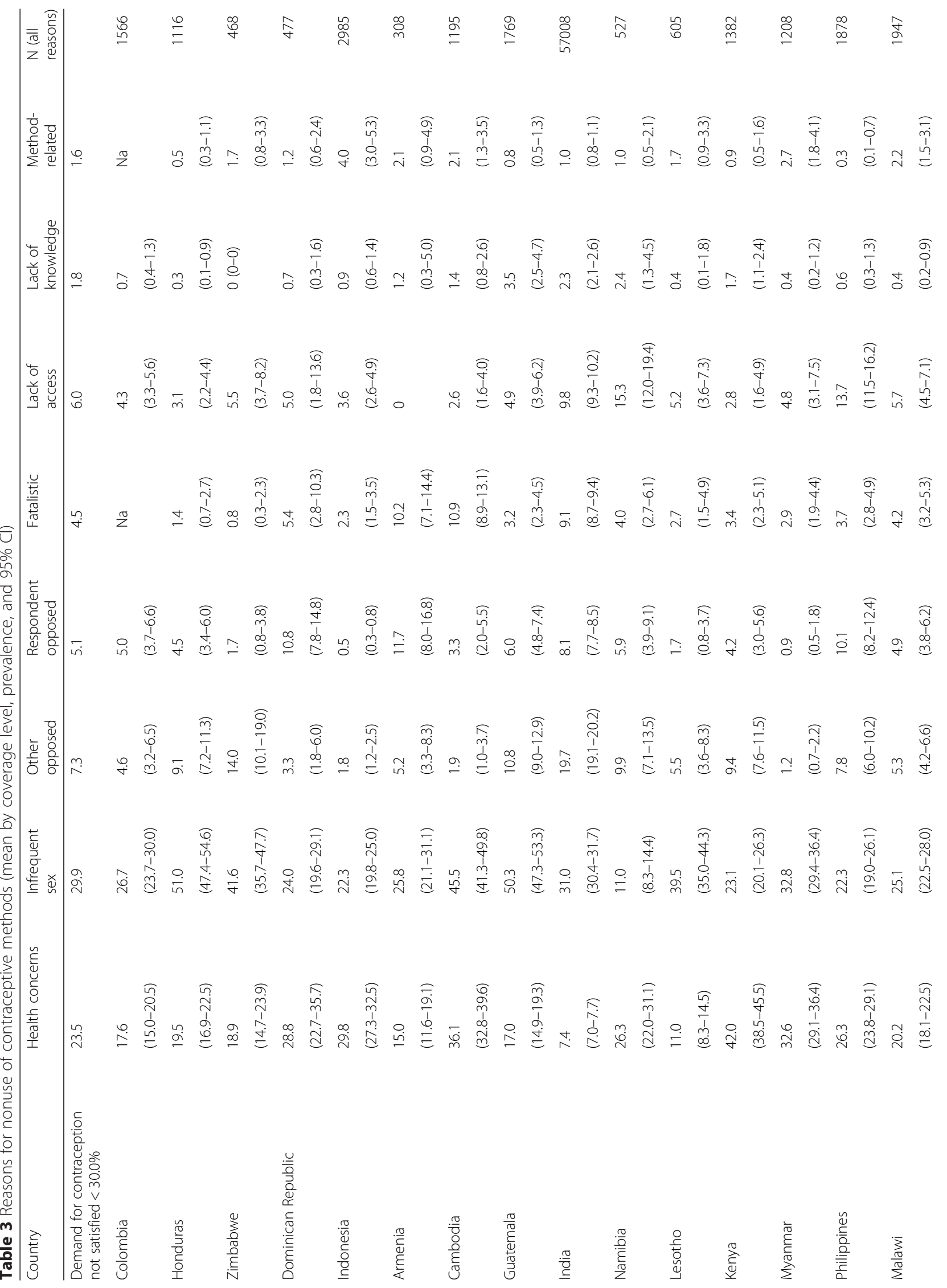




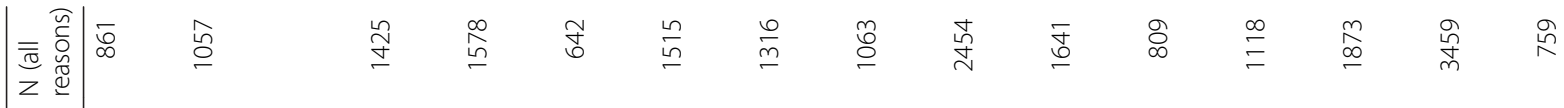

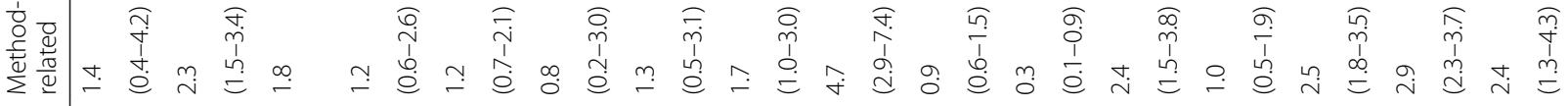

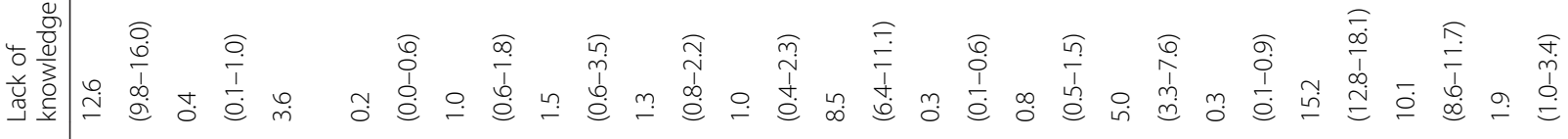

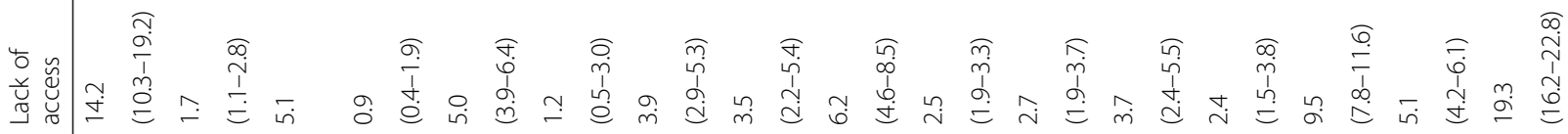

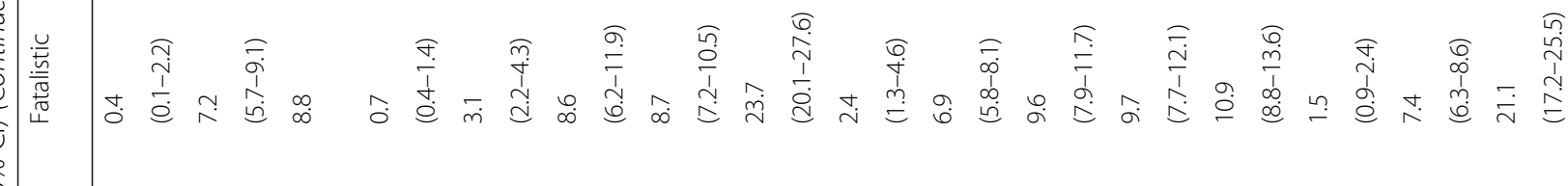

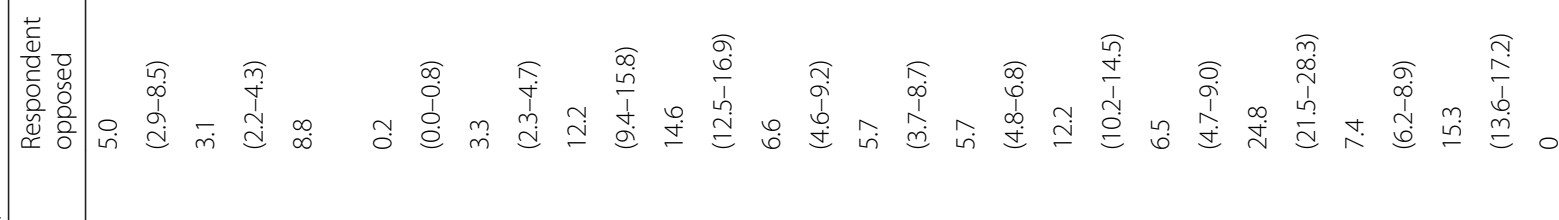

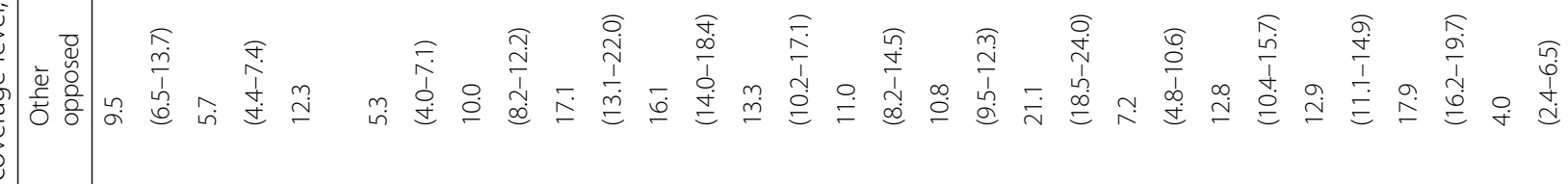

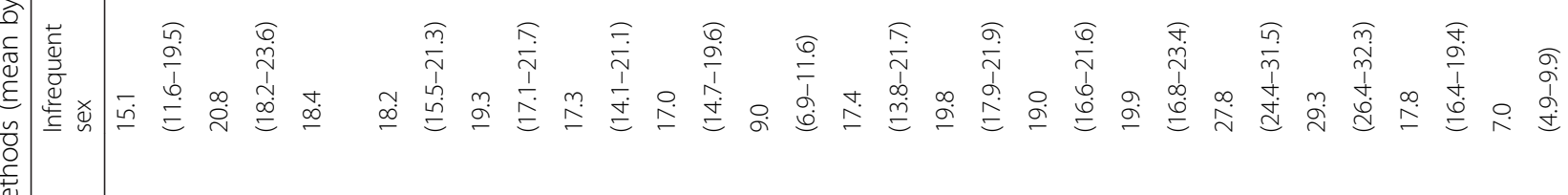

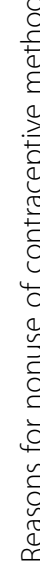

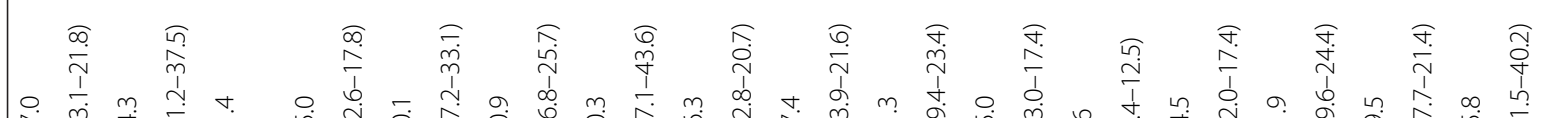

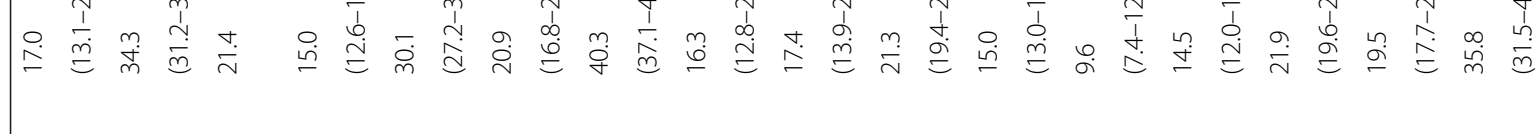




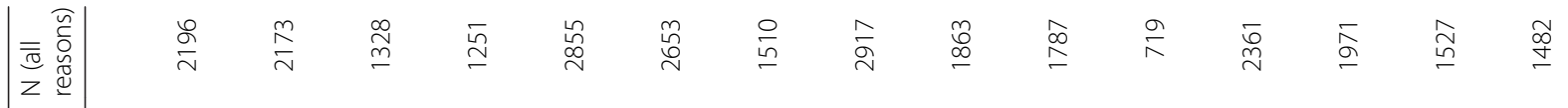

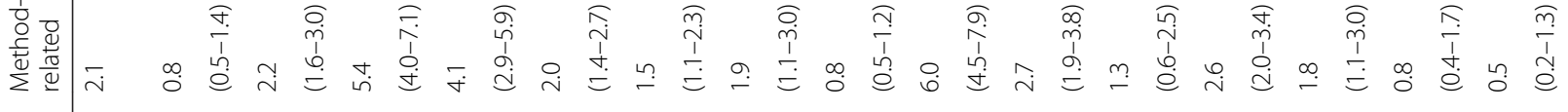

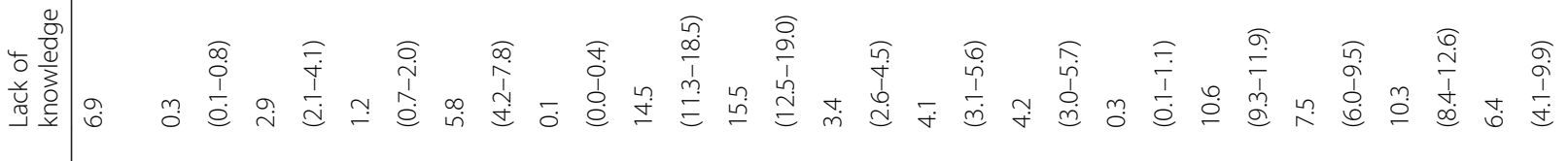

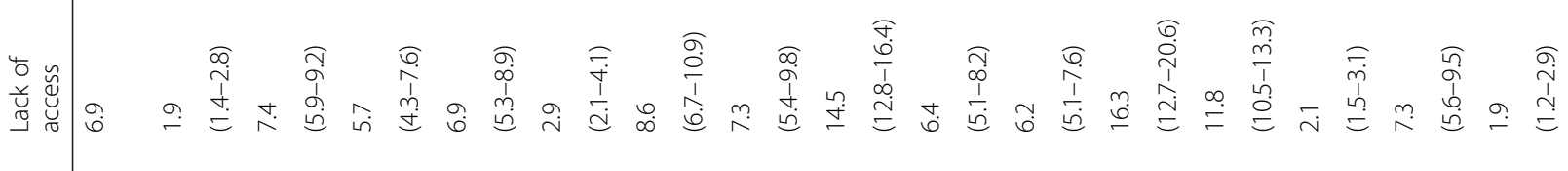

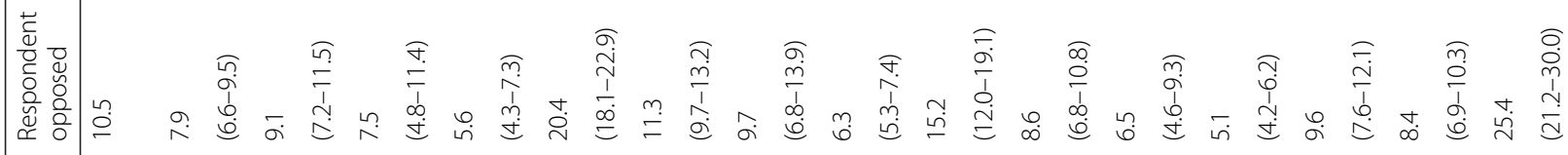

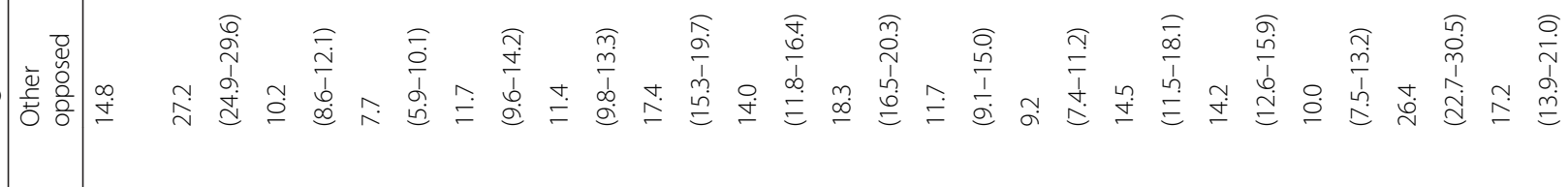

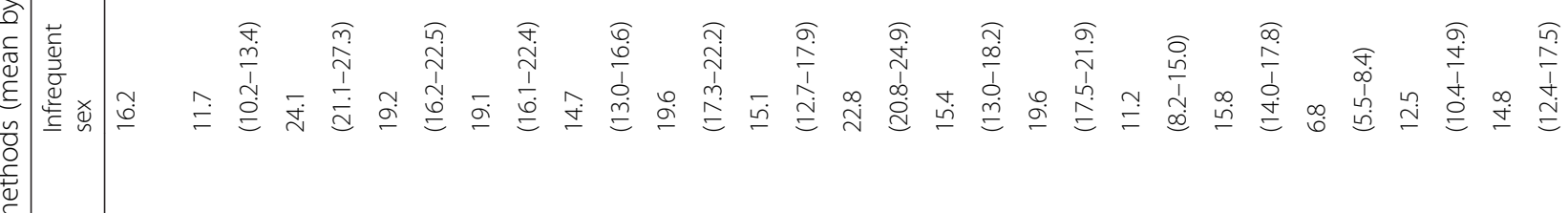

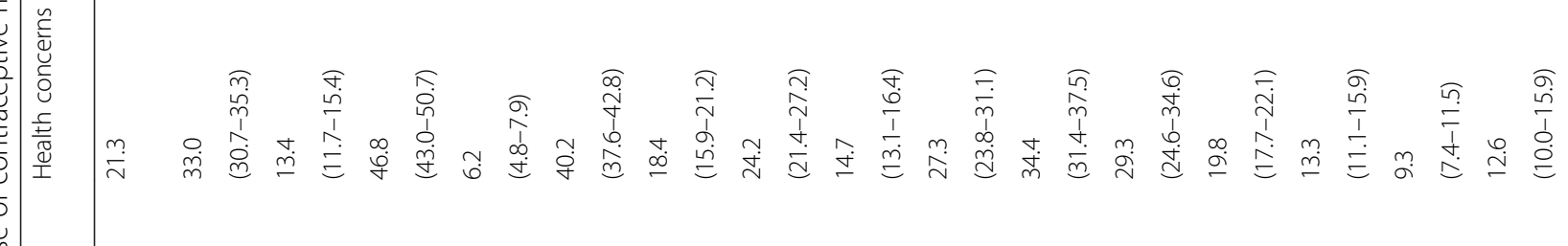

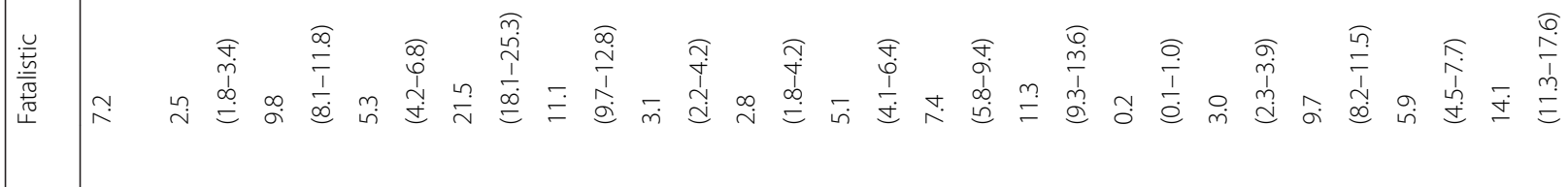




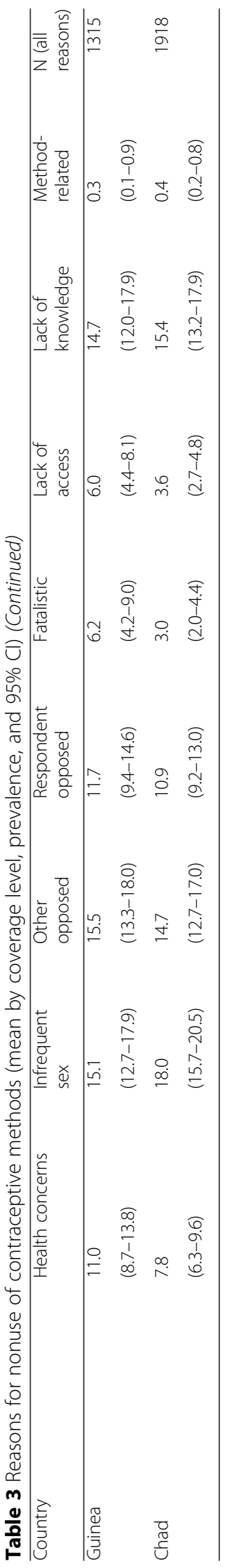




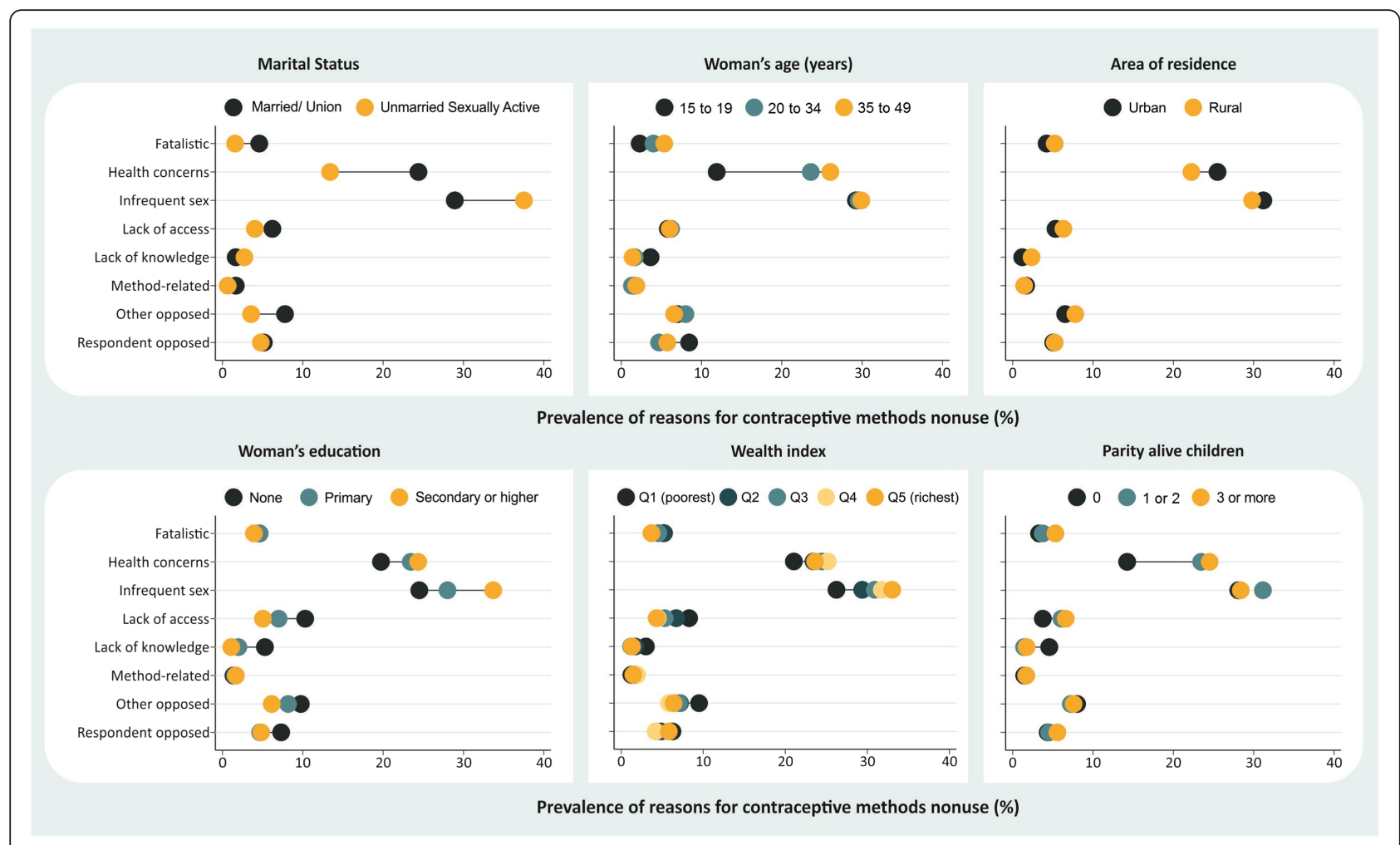

Fig. 1 Reasons for nonuse of contraceptive methods according to stratifiers in countries with demand for contraception not satisfied $<30.0 \%$

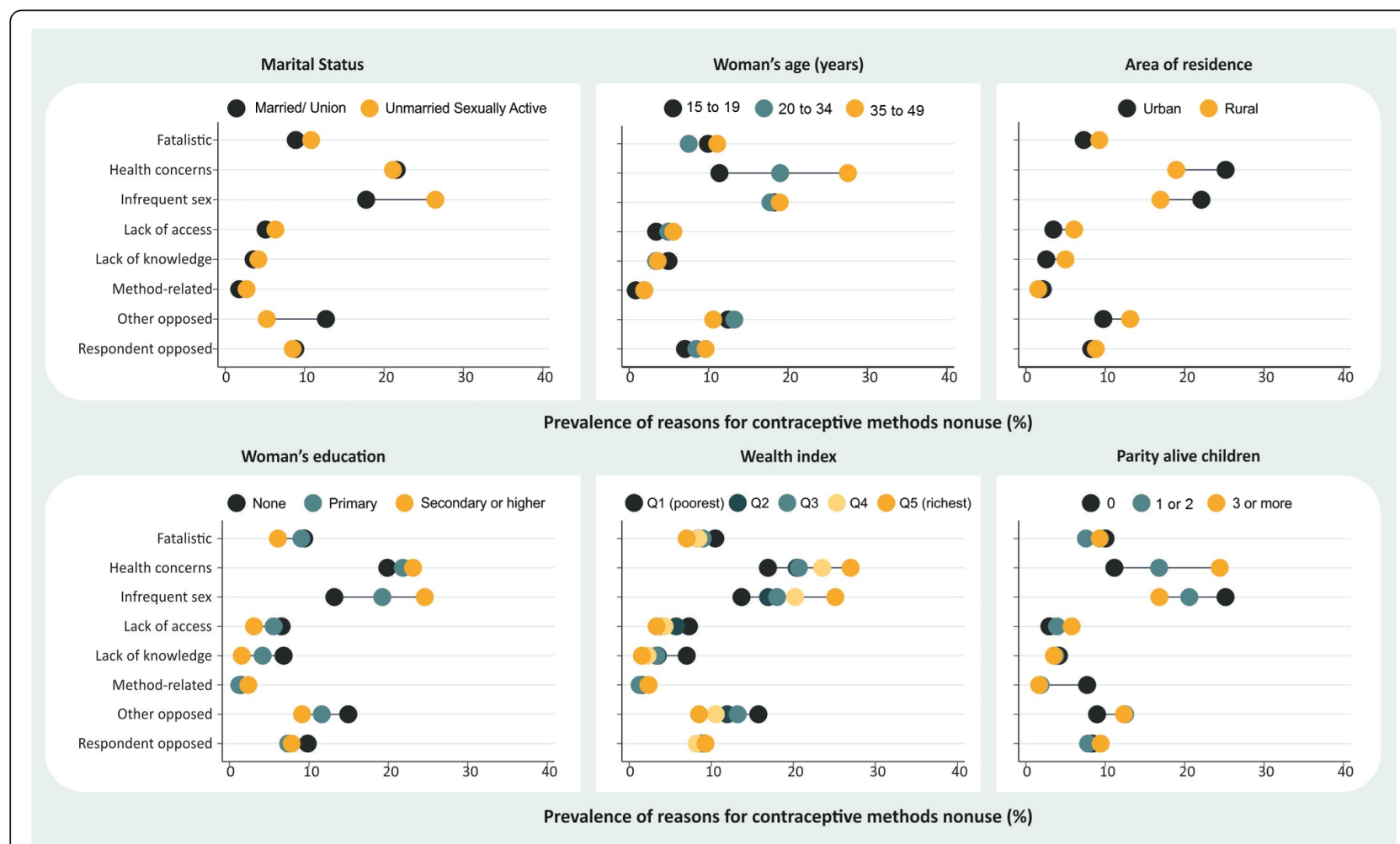

Fig. 2 Reasons for nonuse of contraceptive methods according to stratifiers in countries with demand for contraception not satisfied between 30.0 and $50.0 \%$ 


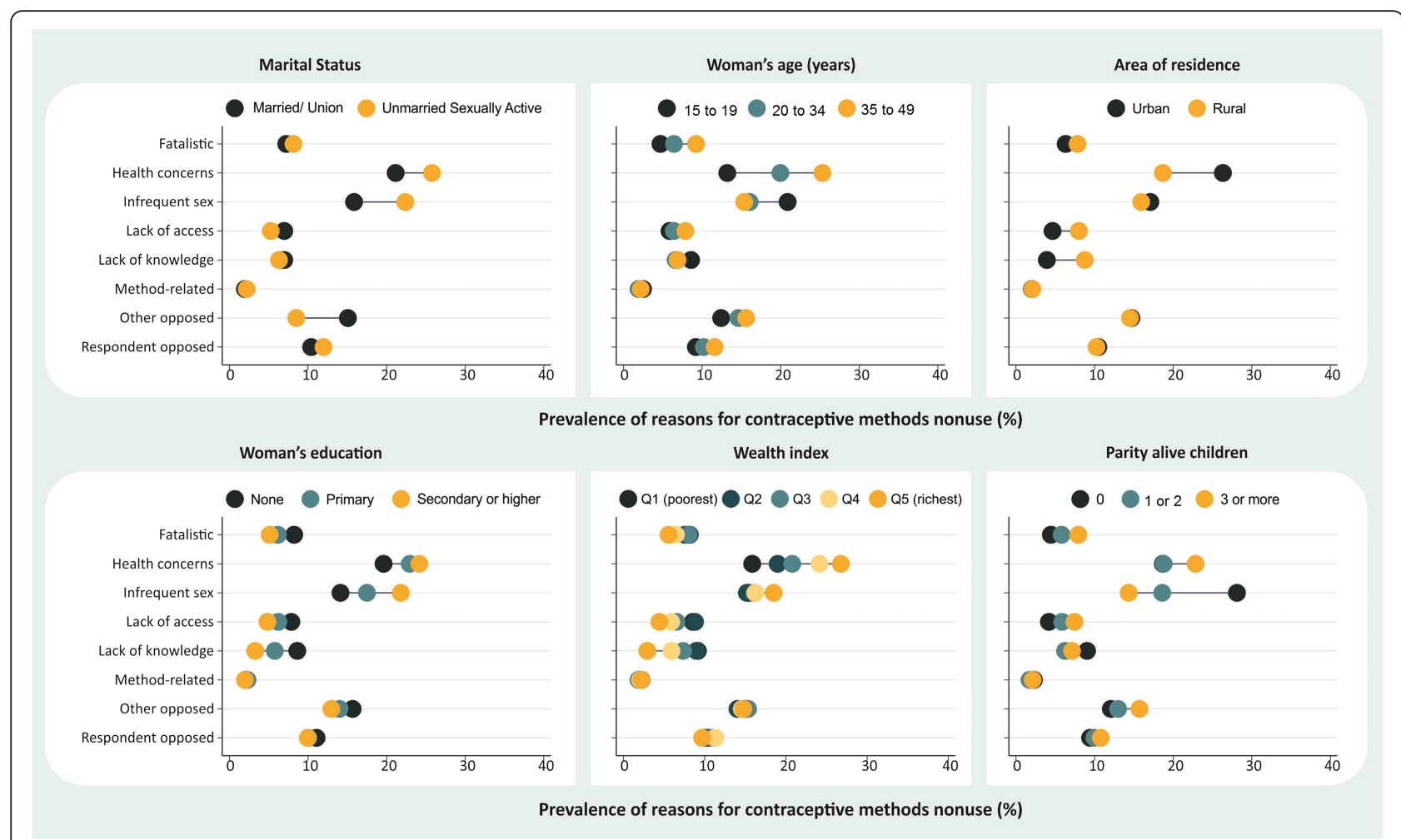

Fig. 3 Reasons for nonuse of contraceptive methods according to stratifiers in countries with demand for contraception not satisfied $>50.0 \%$

of contraception and listen to women's beliefs and opinions so that women can make informed decisions about the most appropriate contraceptive methods for them.

Women who reported "infrequent sex" as a reason for nonuse may consider themselves less likely to get pregnant, as suggested by Sedgh and Hussain [9] and Barot [30]. Over time, women have taken on new roles in society, and there is evidence of declining unmet contraceptive needs [6,31]. Work opportunities may sometimes lead to geographical relocation [9, 32, 33], which may then cause couples to live apart. In this situation, the professional advantage obtained may come at a personal cost with regards to women's reproductive health decisions. These aspects may explain, at least in part, some of our results (for example, why women who were in the highest wealth quintile (fifth quintile) and had more schooling had a higher mean prevalence of nonuse due to "infrequent sex"). It is important to provide these women information on the functioning of the reproductive system and the importance of contraceptive use, and offer them support for reproductive health decisions. Long-acting reversible contraceptives may be a good alternative for these women.

Some women avoid using contraceptives due to "other opposition" which can be their partners, other people from their families or communities, or even their religions. Women sometimes face obstacles in their relationships with their partners (for example, difficulty in negotiating contraceptive use), and this can be inferred from the stratified analysis since in general, the mean prevalence of this reason was higher among married women than among unmarried women. This is striking, as all women should have the right to make their own reproductive decisions. This also highlights the need to empower women, as doing so will allow them to have autonomy over their own bodies and lives and make informed decisions regarding contraception [34].

It is possible that cultural and personal issues, which were not captured in the health surveys, may also be involved in women's decisions to use or not use contraceptive methods. Some women are engaged in homoaffective relationships, which is another aspect that is not evaluated in the surveys. In this case, there would be no concerns regarding using contraception to prevent pregnancy, although the use of condoms, for example, would be essential in preventing sexually transmitted infections. In regard to women who reported a "fatalistic" or "respondent opposed" reason, it is possible that this involves beliefs or other personal issues that require further investigation.

In countries where nonuse due to "lack of access" is high, investments made to increase the availability of contraceptive methods is essential. Beyond access, it is 
also imperative that health care professionals are prepared to provide information on the specific characteristics of existing contraceptive methods to ensure that people can choose the method that best fits their individual needs [23, 35, 36]. However, it is noteworthy that some women face a variety of barriers [7, 37] when attempting to fulfill their reproductive health needs.

Some limitations of the present study must be addressed. First, since countries without information on unmarried, sexually active women were excluded, some regions may have been underrepresented. In other words, the group of countries that were investigated may not represent the entire region or all LMIC. In addition, in presenting means, the data may differ from individual results, as substantial variations were identified. In this sense, it is relevant to pay attention to the data from each individual country to understand what these data reveal about the local reproductive health situation. Being currently pregnant was a filter for the DHS questions regarding reasons for not using contraceptives. However, it is important to understand whether these women had a contraceptive failure or whether they were not using any contraceptive methods (and what the reason was, should they have not been using any methods of contraception). Another limitation is that, by grouping reasons such as nonuse due to religious concerns and nonuse due to partner opposition similarly under "other opposed" (this strategy was adopted because very few women mentioned religious prohibition), it is impossible to detect whether religious constraints predominated in some countries over other persons' opposition. As well, we cannot rule out the possibility of differences in individuals' understandings and interpretations of the survey questions, and thus in the way the themes under investigation were reported.

Nevertheless, the present study also has many strengths, such as the use of recent data (2010-2017) for a large number of countries and the inclusion of information about both married and unmarried women. This provides a comprehensive overview of the reasons for nonuse of contraception, and is a step forward in relation to previous studies $[9,11]$. In addition, the present study only focused on, for the calculation of the indicator, women in need of contraception and provided knowledge on reasons why contraceptive methods are not used, with stratification by subgroups. By directly pinpointing groups in need of interventions, we can better fulfill the contraceptive needs of women.

Understanding the reasons behind why women are not using contraceptives has many potential implications for reproductive health policies. Identifying the opinions of women themselves on the topic and detecting possible difficulties they face may serve as a tool to help professionals from diverse fields keep in mind the importance of increasing access to reproductive health services, empower women to make their own reproductive decisions, and provide necessary information and support to ensure that women are capable of overcoming barriers.

\section{Conclusions}

"Health concerns" and "infrequent sex" were the most frequent reasons for nonuse of contraception in many LMIC, though the prevalence of each reason varied across different countries and subgroups of women. To decrease the prevalence of demand for contraception not satisfied, it is necessary to design, test and implement contextualized interventions. Generally, it is necessary to listen to women's beliefs and opinions, provide women with more information on the importance of using contraceptives to avoid unwanted pregnancies and sexually transmitted infections, inform them of the contraceptive methods available and their side effects, and increase their access to a wide range of contraceptive methods.

\section{Supplementary information}

Supplementary information accompanies this paper at https://doi.org/10. 1186/s12978-019-0805-7.

Additional file 1. Reason respondent opposed according to stratifiers in women (15-49 years) with demand for contraception not satisfied.

Additional file 2. Reason other opposed according to stratifiers in women (15-49 years old) with demand for contraception not satisfied.

Additional file 3. Reason lack of knowledge according to stratifiers in women (15-49 years old) with demand for contraception not satisfied.

Additional file 4. Reason health concerns according to stratifiers in women (15-49 years old) with demand for contraception not satisfied.

Additional file 5. Reason reason lack of access according to stratifiers in women (15-49 years old) with demand for contraception not satisfied.

Additional file $\mathbf{6}$. Reason method related according to stratifiers in women (15-49 years old) with demand for contraception not satisfied.

Additional file 7. Reason fatalistic according to stratifiers in women (15-49 years old) with demand for contraception not satisfied.

Additional file 8. Reason infrequent sex according to stratifiers in women (15-49 years old) with demand for contraception not satisfied.

Additional file 9. Slope Index of Inequality (SII) calculated employing wealth index.

\section{Abbreviations \\ Cl: Confidence Interval; DHS: Demographic and Health Surveys; ISO: International Organization for Standardization; LMIC: Low and middle- income countries; MICS: Multiple Indicator Cluster Surveys; SIl: Slope Index of Inequality}

\section{Acknowledgements}

We would like to thank Jiayue Zheng for her careful revision of the grammatical aspects of the final manuscript.

\section{Authors' contributions}

LRM and FE reviewed the literature, analyzed and interpreted the data obtained from female participants, and wrote the manuscript. FE and AJDB contributed to data interpretation, substantially revised the manuscript, and produced the final figures and tables. MFS conceived the work, supervised 
the project, and participated in all subsequent steps. All authors read and approved the final manuscript.

\section{Funding}

Financial support for the Pelotas International Center for Equity in Health (Centro Internacional de Equidade em Saúde) is provided by the Bill \& Melinda Gates Foundation and the Wellcome Trust. The present work was supported by the Brazilian Funding Agency CAPES (Coordenação de Aperfeiçoamento de Pessoal de Nivel Superior) - code 001. MFS is a Research Fellow funded by the Brazilian National and Scientific Council (Conselho Nacional de Desenvolvimento Científico e Tecnológico, CNPq) and the Rio Grande do Sul State Research Foundation (Fundação de Amparo à Pesquisa do Estado do Rio Grande do Sul, FAPERGS).

\section{Availability of data and materials}

The Demographic and Health Surveys (DHS) used in the present analyses are publicly available at < https://dhsprogram.com/data/available-datasets.cfm>.

\section{Ethics approval and consent to participate}

Approval by specific research ethics committees is waived for studies that use publicly available data such as the Demographic and Health Surveys (DHS). Research ethics approval and consent were secured prior to DHS data collection, with confidentiality guaranteed at all stages.

\section{Consent for publication}

Not applicable.

\section{Competing interests}

The authors declare that they have no competing interests.

\section{Author details}

${ }^{1}$ Postgraduate Program in Epidemiology, Federal University of Pelotas, Marechal Deodoro, 1160 - 3rd floor. Centro, Pelotas 96020-220, Brazil. ${ }^{2}$ International Center for Equity in Health, Federal University of Pelotas, Pelotas, Brazil.

Received: 1 May 2019 Accepted: 3 September 2019 Published online: 11 October 2019

\section{References}

1. United Nations. Transforming our world: the 2030 Agenda for Sustainable Development [internet]. 2015

2. Countdown to 2015, The health metrics network, WHO. Monitoring maternal, newborn and child health: understanding key progress indicators, vol. 2011. Geneva: World Health Organization; 2011.

3. Brown W, Druce N, Bunting J, Radloff S, Koroma D, Gupta S, et al. Developing the "120 by 20 " goal for the global FP2020 initiative. Stud Fam Plan. 2014;45(1):73-84

4. Lissner $\mathrm{CL}$, Ali M. Study group on contraceptive financing M. systematic reviews of mechanisms for financing family planning: findings, implications, and future agenda. Stud Fam Plan. 2016:47(4):295-308.

5. Sharma S, Gribble JN, Menotti EP. Creating options in family planning for the private sector in Latin America. Rev Panam Salud Publica. 2005; 18(1):37-44.

6. Alkema L, Kantorova V, Menozzi C, Biddlecom A. National, regional, and global rates and trends in contraceptive prevalence and unmet need for family planning between 1990 and 2015: a systematic and comprehensive analysis. Lancet. 2013:381(9878):1642-52.

7. Scientific and Technical Advisory Group (STAG), The Gender and Rights Advisory Panel (GRAP). Statement on the promotion, protection and fulfilment of sexual and reproductive health and rights. Geneva: UNDP/ UNFPA/UNICEF/WHO/WORLD BANK Special Programme of Research, Development and Research Training in Human Reproduction; 2017.

8. Guttmacher Institute. Adding It Up: Investing in Contraception and Materna and Newborn Health. New York: Gutmacher Institute; 2017.

9. Sedgh $G$, Hussain R. Reasons for contraceptive nonuse among women having unmet need for contraception in developing countries. Stud Fam Plan. 2014;45(2):151-69.

10. Raj $A$, McDougal L. Leaving no one behind: can the family planning estimation tool help? Lancet Glob Health. 2017;5(3):e242-e3.
11. Bradley SE, Croft TN, Fishel JD, Westoff CF. Revising unmet need for family planning. 2012. DHS analytical studies no. 25. ICF International: Calverton; 2012

12. Rutstein SO, Rojas G. Guide to DHS statistics: demographic and health surveys methodology. ORC Macro: Calverton; 2006.

13. Barros AJD, Boerma T, Hosseinpoor AR, Restrepo-Méndez MC, Wong KLM, Victora CG. Estimating family planning coverage from contraceptive prevalence using national household surveys. Global Health Action. 2015; 8(1):29735.

14. Ewerling F, Victora CG, Raj A, Coll CV, Hellwig F, Barros AJ. Demand for family planning satisfied with modern methods among sexually active women in low-and middle-income countries: who is lagging behind? Reprod Health. 2018:15(1):42.

15. Rutstein SO, Johnson K. The DHS wealth index. DHS comparative reports no. 6. ORC Macro: Calverton; 2004.

16. ICMd S, Restrepo-Mendez MC, Costa JC, Ewerling F, Hellwig F, Ferreira LZ, et al. Measurement of social inequalities in health: concepts and methodological approaches in the Brazilian context. Epidemiol Serv Saúde. 2018:27:e000100017

17. Stata Statistical Software. Release 13. College Station: StataCorp LP; 2013.

18. Creanga AA, Gillespie D, Karklins S, Tsui AO. Low use of contraception among poor women in Africa: an equity issue. Bull World Health Organ. 2011:89:258-66

19. The World Bank Group. Fertility rate, total (births per woman). Washington, DC: The World Bank; 2019. [Available from: https://data.worldbank.org/ indicator/SP.DYN.TFRT.IN?locations $=$ Z

20. Guzmán JM, Rodríguez J, Martínez J, Contreras JM, González D. The demography of Latin America and the Caribbean since 1950. Population. 2006;61(5):519-620.

21. Sarley D, Dayaratna V, Abramson W, Gribble J, Quesada N. Options for contraceptive procurement: lessons learned from Latin America and the Caribbean; 2006

22. Santelli J, Rochat R, Hatfield-Timajchy K, Gilbert BC, Curtis K, Cabral R, et al. The measurement and meaning of unintended pregnancy. Perspect Sex Reprod Health. 2003;35(2):94-101.

23. Curtis KM, Jatlaoui TC, Tepper NK, Zapata LB, Horton LG, Jamieson DJ, et al. US selected practice recommendations for contraceptive use, 2016. 2016.

24. Gipson JD, Koenig MA, Hindin MJ. The effects of unintended pregnancy on infant, child, and parental health: a review of the literature. Stud Fam Plan. 2008;39(1):18-38.

25. Le HH, Connolly MP, Bahamondes L, Cecatti JG, Yu J, Hu HX. The burden of unintended pregnancies in Brazil: a social and public health system cost analysis. Int J Women's Health. 2014;6(1):663-70.

26. Cerqueira-Santos E, SdS P, EDB DS, Koller SH. Gravidez na adolescência: análise contextual de risco e proteção. Psicologia em estudo Maringá Vol 15, n 1; 2010. p. 73-85

27. Kost K, Forrest JD, Harlap S. Comparing the health risks and benefits of contraceptive choices. Fam Plan Perspect. 1991;23:54-61.

28. National Research Council (US) Committee on Population. Contraception and Reproduction: Health Consequences for Women and Children in the Developing World. Washington (DC): National Academies Press (US); 1989

29. Thorne S, MacGregor A, Nelson-Piercy C. Risks of contraception and pregnancy in heart disease. Heart. 2006;92(10):1520-5.

30. Barot S. Sexual and reproductive health and rights are key to global development: the case for ramping up investment; 2015.

31. Darroch JE, Singh S. Trends in contraceptive need and use in developing countries in 2003, 2008, and 2012: an analysis of national surveys. Lancet. 2013;381(9879):1756-62

32. Aluttis C, Bishaw T, Frank MW. The workforce for health in a globalized context-global shortages and international migration. Glob Health Action. 2014;7(1):23611.

33. Siddiqui T. Migration and gender in Asia. United Nations Expert Group Meeting on International Migration and Development in Asia and the Pacific, Economic and Social Commission for Asia and the Pacific. Bangkok: Population Division; 2008. Citeseer

34. Ewerling F, Lynch JW, Victora CG, van Eerdewijk A, Tyszler M, Barros AJ. The SWPER index for women's empowerment in Africa: development and validation of an index based on survey data. Lancet Glob Health. 2017;5(9):e916-e23.

35. World Health Organization (WHO). Medical Eligibility Criteria for Contraceptive Use. 5th edition. Geneva: World Health Organization; 2015. 
ISBN 9789241549158. Available at https://apps.who.int/iris/bitstream/ handle/10665/181468/9789241549158_eng.pdf?sequence $=9$.

36. World Health Organization Department of Reproductive Health and Research (WHO/RHR) and Johns Hopkins Bloomberg School of Public Health/Center for Communication Programs (CCP) KfHP. Family Planning: A Global Handbook for Providers (2018 update). Baltimore and Geneva: CCP and WHO; 2018

37. Asekun-Olarinmoye E, Adebimpe W, Bamidele J, Odu O, Asekun-Olarinmoye I, Ojofeitimi E. Barriers to use of modern contraceptives among women in an inner city area of Osogbo metropolis, Osun state, Nigeria. Int J Womens Health. 2013:5:647.

\section{Publisher's Note}

Springer Nature remains neutral with regard to jurisdictional claims in published maps and institutional affiliations.

Ready to submit your research? Choose BMC and benefit from:

- fast, convenient online submission

- thorough peer review by experienced researchers in your field

- rapid publication on acceptance

- support for research data, including large and complex data types

- gold Open Access which fosters wider collaboration and increased citations

- maximum visibility for your research: over $100 \mathrm{M}$ website views per year

At BMC, research is always in progress.

Learn more biomedcentral.com/submissions 